\title{
Social Media to Enhance Design Practices: Exploring the Learning Experience of Undergraduate Design Students
}

\author{
Yun Yi Tan \\ Centre for Instructional Technology \& Multimedia \\ Universiti Sains Malaysia \\ Penang, Malaysia yunyi.tan@usm.my
}

\author{
Allan H.K. Yuen \\ Faculty of Education \\ The University of Hong Kong \\ Hong Kong hkyuen@hku.hk
}

\begin{abstract}
To succeed as pioneers in the creative industry, it is crucial for design students in higher education institutions to understand the practical skills, creative approaches and attitudes needed. However, design students tend to face difficulties in developing their potential skills and discovering their creative passion due to the limited resources and room for experimentation within the confined walls of their studio classrooms. This paper explores how social media could be utilized to enhance their learning experiences. We present case studies of two undergraduate design students who have used a social media platform (SMP) that are specifically built for the community of designers - Behance, to facilitate their design learning. Findings are drawn upon an in-depth investigation into their uses of Behance over a period of 14 weeks in a higher education institution in Malaysia. The study reveals that the integration of social media could enhance the design learning process of the design students and potentially improve their pathways into the creative industry.
\end{abstract}

Keywords: design learning, design practices, social media,creativity development.

\section{INTRODUCTION}

Social media is no longer a new phenomenon on the rise. With the advent of the Internet and various digital technologies, the constructivism paradigm has led to the development of computer-supported learning interventions and learning environments. This has suggested new ways to learning and offered possibilities to alternative learning environments. In the education sector, the importance of social media is indeed being increasingly acknowledged for its ability to elevate the performance of students and enhance their engagement level $[3,5]$. They are also known for their abilities in enhancing students' learning experiences [2] by enabling plenty of opportunities for engagement and collaboration $[4,8,16]$. Indeed, the new web technologies have been reportedly used to facilitate sharing of experts' experiential knowledge [13]. For example, instead of being just readers, everyone can now contribute and publish their own content in a collaborative manner. The contents were then shared onto social media sites such as Digg, Tumblr and Pinterest [11]. [6] asserted that users are able to share their experience by producing their personal content on the network. By this mean, tacit knowledge could conveniently be converted to explicit knowledge [1]. Along with the rise of mobile technologies, social media has increased the possibility of ubiquitous learning that offers more flexibility to learners $[9,14]$.

In an effort to bridge the gap between academia and practices, design institutions have developed joint efforts with the industry in outlining their educational activities. For instance, experts from the industries were invited as members of the evaluation committee for design education curricula and also, as guest lecturers in classrooms to share their bits of knowledge from the 'real' world [15]. The institutions are using this approach to expand the teaching and learning channels, and also acquire to the tacit knowledge that resides in the actions of experts. However, this method may not always be achievable and cost effective.

Therefore, it is argued that higher institutions should develop a more progressive method to enhance the interaction between learners, industry experts and the creative community, out of the customary approach to creative education by harnessing the potential of social media and social networking sites. Existing studies have reported on the study of social media and its use in educational settings. Nevertheless, there are still little research on its use for bolstering design education and creative community. Hence, this study is an attempt to further exploit the potential of social media technology in enhancing the development of design and creativity from the perspectives of design students. To be specific, this study intends to examine the factors in a context that supported the students' use of social media platform that are developed specifically for the designer community for design learning purposes. The research questions we therefore address in this study are:

1) What are the characteristics of the social media platform that support the design students' learning process?

2) How do the social media platform enhance the learning experience of the design students?

For this study, we have used the term social media platform (SMP) to refer to the web-based or mobile application that can be utilized to integrate or facilitate a community with enabling social media features such as content creation and networking.

\section{METHODOLOGY}

Prior to this study, we conducted three cases-in-point to identify the most suitable platform to be used. Behance was chosen based on the findings from the cases-inpoints and also considerations and suggestions 
highlighted by the course instructor. Firstly, Behance is acquired by a well-known company behind the major multimedia and creativity software products that is used by various design agencies and learning institutions Adobe. This enables users to have seamless connection between Adobe tools and Behance services. Secondly, the user interface of Behance is less complicated compared to other SMPs where users are able to see all features without needing to dig into the hidden links. Third, there is a wider community in Behance consisting of individual professionals, design agencies, schools and corporate companies.

This study was conducted in a local higher education institution in Malaysia, focusing on two undergraduate students who were undertaking a design related course. Following the qualitative paradigm, the study utilized the combination of case study and Straussian grounded theory methodological approach. As suggested by [6], the Straussian approach tends to be more useful when studying individuals. The use of this approach to study data helps the researcher to understand the social context and explain how the design students iteratively learn and respond to the given design problems. Findings were drawn upon an in-depth investigation into two design students' uses of Behance over a period of 14 weeks.

We have worked closely with the course instructor before the commencement of the new semester and discussed on how Behance could be integrated into the course structure. The instructor was given the opportunity to take full charge of the course structures and activity plans. Observational visits were made to design studio throughout the 14-weeks course period. Observations were scheduled twice a week, once during lecture session and once during tutorial session. During each visit, the participating students was observed in a series of alternating 20-minutes occasions (15-minute observation, 5minute writing field notes). We observed the student activities that took place in Behance and documented their learning processes through field notes. The design work entries uploaded by the students were captured as evidences to trace how the platform is being used. Following their participation in the SMP, the design students were interviewed through an in-depth, semi-structured interview conducted at the end of the semester.

\section{FINDINGS}

During the in-depth interviews, the design students P1 and P2, were asked to elaborate on the factors that encouraged them to use Behance to help with their design projects or assignments. Hence, this section presents the characteristics of Behance that support design learning and design practices for the participating design students. The characteristics are conceptualised based on the design students' responses when using SMP throughout the research study. The conceptualised characteristics are: (a) resources for design learning, (b) intrinsic motivation, (c) performance monitoring, and (d) exposure opportunities. In this section, each of the characteristics will be described.

\section{A. Resources for design learning}

The most dominant characteristic that encouraged the students to use the SMP during this research study was 'resources for design learning'. When asked why they started using Behance, both students mentioned that they chose to use it because its features supported their design learning practices in obtaining resources and references, sharing own works, and soliciting feedback.

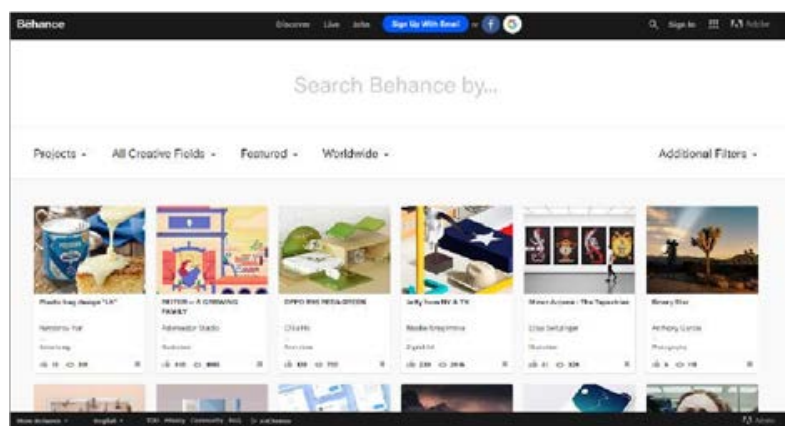

Figure. 1. "Search” feature on Behance.

a) Explore resources: Both design students pointed out that one of the main reasons that triggered their interest in using Behance during this research study was being able to look for references and inspirations. P1 benefited from the search and explore feature of Behance. P1 mentioned that she chose to use social media platforms, like Behance, to speed up her designing process and get design inspirations. She said, "If there was no internet or such social media platforms, I would have to come up with ideas that are solely based on my life experience. I could not get the inspirations anymore. It would be like having to create an artwork based on what I have experienced and the things around me." She also mentioned that having references and design inspirations helped to stir up her imagination. Previously, she had used Google images to browse for design inspirations but she could not find what she was looking for. She said, "I could get most of what I was looking for on Behance. Search results from Google images were just general artworks." She explained that she could not find any references to be used for her class assignments on Google images. She added, "For example, I wanted landscape and panorama art references for our recent assignment. I could not find anything on

Google images, but I could find plenty of them on Behance."

P2 asserted that references helped him to create better artworks. He would learn from other people's artworks too and tried creating artworks of similar standards. He said, "If I were to create my works without any references, it would be dull upon completion." He also mentioned that his art styles were influenced by the references he found. Consequently, he decided to use Behance to support his design process. It was also easier and cost saving for him to get the references online. He said, "It would be harder if I were to do it out of the platform. I might need to buy design books to get the references instead."

b) Sharing of own works: The design students mentioned that they chose to use Behance because they wanted to showcase their works. P2 pointed out that they would now use Behance as a tool to show their artworks to the public, especially people from the industry. P1 said, "After graduating, I can actually show my work 
progresses to my potential employers during the interview. I can show them how I've improved from here and all the way up throughout my studying years." She added that Behance helped her to see improvements in her works.

c) Soliciting feedback: P2 mentioned that the main benefit of using Behance was being able to gain various constructive feedbacks from people in the field, especially the industry designers who would usually be busy working.

Instead of just relying on their instructor's feedbacks, P2 asserted that it is also important to gain feedbacks from wider audiences because different people have different preferences and styles. Although he did not know the industry designers personally, he was pleased with the feedbacks received. He said, "The comments were mostly constructive. When someone told me my works were nice, he highlighted the parts of my works that captured their attention too." P2 added that the critiques were also useful because they were descriptive enough and helped him to revise his works. P1 shared the same opinion on her uses of Behance. She mentioned that her main intention of using Behance in their design learning was to improve their design skills and create better artworks in the future. Throughout the 14-weeks course, seven projects were uploaded and she received a total of four feedbacks from the industry designers.

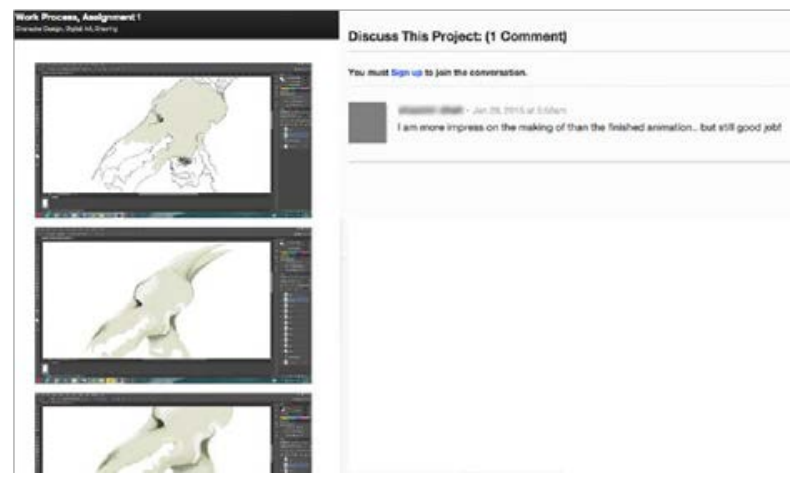

Figure. 2. Screenshot of feedback on P1's profile.

\section{B. Intrinsic motivation}

The second noticeable factor that most design students mentioned was closely related to the creation of various positive emotions within them when using Behance. At the beginning of this research study, the design students were told that their use of the SMP would not affect their grades and there would not be any prize or rewards for their participations. Nevertheless, they have participated actively and used Behance as part of their design learning process..

They pointed out that they were motivated to learn and improve themselves by using Behance because they wanted to be more skilled and elevate their competency. P1 highlighted that viewing other users' works on Behance inspired her to start creating her own artworks. Moreover, the feedbacks she received on her artworks provided the moral support to move ahead in improving her design skills. She said, "The feedbacks gave me the moral support that I need to go forward and create more artworks in the future... to do better, to improvise." When asked how the feedbacks helped her, she described, "If it's an appraisal comment, they will make you feel happier. They will boost your self-esteem and everything, and you will feel encouraged to do more. If it's a constructive criticism, I will just take it positively and push myself to do better. It boosts your determination to do better too." She added that the feedback soliciting process on Behance made her designing tasks more meaningful, which offered the basis for her design progress. She said, "If you're just doing it alone, there's no point. Doing it alone is like wasting your talent." Similarly, P2 mentioned that showcasing his artworks on Behance gave him a purpose to keep creating more new artworks. He was able to seek feedbacks on his artworks, which persuaded him to be more eager in sharing his works. To P2, feedbacks that encouraged him to improvise his design skills made him feel like his design outcomes were being anticipated. Besides that, P2 also remarked that browsing his classmates' work on Behance helped in pushing him forward to complete his assignments given by the instructor. Interestingly, despite being challenged and competitive, P2 would also assist his friends to improve their skills too. He would use the references and working examples found on Behance to elevate their confidence in accomplishing their design tasks and assignments. what I wanted to express.”

\section{Performance monitoring}

Another significant reason that motivated the students to use Behance was a feature of the platform that helped them to monitor their own performances. They shared the same opinions about the appropriateness of using Behance as a platform to host their online portfolio for future work or internship purposes. They all pointed out that Behance is a more suitable place to start building their professional images and reputation because of its layout design.

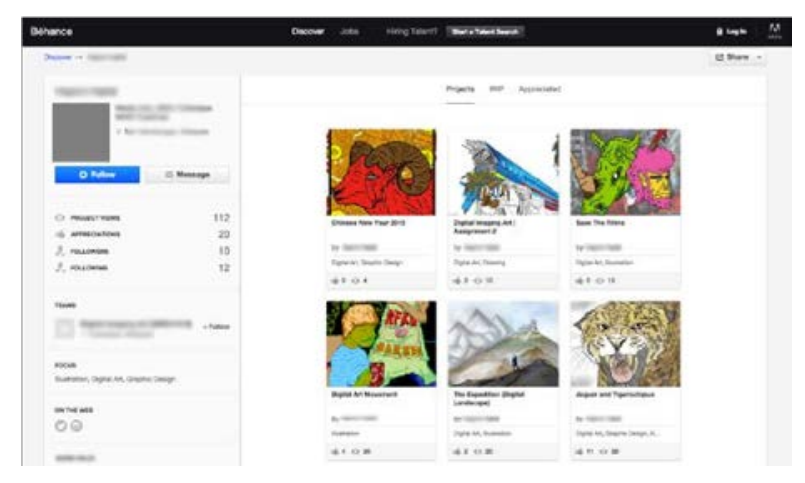

Figure. 3. Screenshot of P2's Behance profile.

P1 remarked that she was able to see her work improvements through her use of Behance. She would still continue using Behance as part of her design practices, although it was not a requirement from her design instructor, because she wanted to maintain it as her working portfolio. She said, "I would keep on uploading my works and maybe, when I graduate, I can actually show my potential employer during my interview. I would show them how I've improved from my first day till my graduation day." $\mathrm{P} 2$ also thinks that it would be an advantage to a designer to construct his own 
identity with the help of social media platforms. He mentioned that it would be easier to get his work noticed by prospective clients or employers with a strong online identity.

\section{Exposure opportunities}

Students of both classes explained that they were more engaged with Behance because they saw it as an opportunity to get them exposed to the industry world and a means to secure job opportunities. This data is characterized as exposure opportunities. The majority of the Class B students mentioned that they hoped to get discovered by their potential employers and that Behance increased their chances of getting hired upon graduation.

P1 highlighted that it was one of the features of Behance that motivated her to update her designs frequently. She was one of the participants who uploaded most artworks that were not assignments onto her Behance profile. She said, "I saw opportunities when I see the 'Talent Search' feature. So, I should be putting my stuff in my profile." The 'Talent Search' feature is a recruitment tool that allows employers to reach out to the artists and designers via job advertisements or through private searches. They would be able to get recommendations for potential candidates they might want to hire from Behance itself, or conduct their own searches according to the candidates' styles, location, and types of created projects. She added that exposing her works to the Internet world is crucial in the process of becoming an artist or a designer. With the help of the Internet, she hopes to gain recognition for every work she creates. She said, "I want people to know that I can do this, and they can hire me for my services. Then I can earn my bread, without depending on anyone else." Towards the end of her interview session, she asserted that she enjoyed having the involvement of industry designers in her design learning process. Besides enhancing the chances of acquiring more job opportunities, she was able to learn more about the creative industry directly from the professionals.

On the other hand, P2 mentioned that he was persuaded into using Behance because it is currently a trend to get noticed through the use of social media platforms. He said, "This is the age of the Internet. People would see what you've posted, regardless of the types of social media platforms." He used his friend's experience, where his friend became famous after engaging in one of the platforms, as an example to illustrate the effectiveness of social media platforms. According to $\mathrm{P} 2$, his friend received more recognition for his photography works, although the photographs taken were different from his other works. It was the social media platform that contributed to his popularity and helped gathered followers. He said, "He shared and exposed his works to the public regularly. That was how people got to know him." He added that the huge number of followers has enticed the public to believe that his works were extraordinary.

\section{DISCUSSION AND CONCLUSION}

From the aforementioned results presented, several conclusions could be drawn. Overall, Behance has fostered creativity and is helpful in enriching design learning. It has the potential to expand the students' expertise and the development of their creative arts. This study suggested that the students' motivation to use the SMP was strongly mediated by their learning goals. The students have grasped the resources available on Behance and used them to support their designing tasks. They have also shared their own resources in return. [12] posits that one of the crucial goals in education is encouraging students to monitor their own performance. Specifically, students must be able to recognize criteria that define what good performance is and evaluate their own work if they were up to the set standards. In this study, it was found that the SMP has also offered support for students to monitor and evaluate their own performance through constant comparison to other users especially their classmates and peers of their own level. The two cases also demonstrated that the students' improvements was influenced by the culture of competition. According to [10], competition as one of the factors that would contribute to individuals' intrinsic motivation.

There are several limitations in this study that should be noted. Due to the qualitative nature of this study, the results reported could not be generalized to all design students in higher education institutions. Ways on how the design students approached the SMP may be different if future studies are conducted in varying culture context. Our findings do not imply the presumption that all design related courses should integrate the use of SMP like Behance to elevate design education. Rather, we would like to argue that the strength of social media technology should be taken full advantage of to enhance designlearning in higher education.

\section{REFERENCES}

[1] Chatti, M. A., Jarke, M., \& Frosch-Wilke, D. (2007). The future of elearning: a shift to knowledge networking and social software. International journal of knowledge and learning, 3(4), 404-420.

[2] Corso, R. D. \& Robinson, H. R. (2013) Enhancing Creative Thinking Abilities Through the Use of Social Media. International Journal of Knowledge, Innovation and Entrepreneurship, 1 (1), 92-105.

[3] Dunlap, J. C., \& Lowoenthal, P. R. (2009). Tweeting the night away: Using Twitter to enhance a social presence. Journal of Information Systems Education. 20(2), 129-136

[4] Greenhow, C. (2011). Online social networks and learning. On the Horizon, 19(1), $4-12$.

[5] Heiberger, G., \& Harper, R. (2008). Have you Facebooked Astin lately? Using technology to increase student involvement. New directions for student services, 2008(124), 19-35.

[6] Jiao, Y., Gao, J., \& Yang, J. (2015). Social value and content value in social media: two ways to flow. Journal of Advanced Management Science, 3(4), 299 - 306.

[7] Lehmann, H.P. (2001) Using grounded theory with technology cases: distilling critical theory from a multinational information systems development project. Journal of Global Information Technology Management, 4, 45-60.

[8] Leppisaari, I., Maunula, M., Herrington, J. \& Hohenthal, T. (2011). Developing More Authentic e-Courses: Working Life Mentoring through Social Media. Proceedings of World Conference on Educational Multimedia, Hypermedia and Telecommunications 2011, 1368-1377.

[9] Li, Q., Lau, R. W., Popescu, E., Rao, Y., Leung, H., \& Zhu, X. (2016). Social Media for Ubiquitous Learning and Adaptive Tutoring [Guest editors' introduction]. IEEE MultiMedia, 23(1), 18-24.

[10] Malone, T. W., \& Lepper, M. R. (1987). Making learning fun: A taxonomy of intrinsic motivations for learning. Aptitude, learning, and instruction, 3(1987), 223-253.

[11] McLoughlin, C., \& Lee, M. J. (2007). Social software and participatory learning: Pedagogical choices with technology 
affordances in the Web 2.0 era. ICT: Providing choices for learners and learning. Proceedings ascilite Singapore 2007, 664675.

[12] Nicol, D.J. \& Macfarlane-Dick, D. (2006) Formative assessment and selfregulated learning: a model and seven principles of good feedback practice. Studies in Higher Education. 31(2), 199-218.

[13] Panahi, S., Watson, J., \& Partridge, H. (2012). Social media and tacit knowledge sharing: Developing a conceptual model. World academy of science, engineering and technology, (64), 10951102.

[14] Pearce, N., \& Learmonth, S. (2013). Learning beyond the Classroom: Evaluating the Use of Pinterest in Learning and Teaching in an Introductory Anthropology Class. Journal of Interactive Media in Education.

[15] Suwannatat, P., Anuntvoranich, P., \& Chandrachai, A. (2012). University and Animation Industry Collaboration: New Product Development Process.

[16] Treem, J. W., \& Leonardi, P. M. (2013). Social media use in organizations: Exploring the affordances of visibility, editability, persistence, and association. Annals of the International Communication Association, 36(1), 143-189. 